\title{
Prevalence of bacterial genotypes and outcome of bovine clinical mastitis due to Streptococcus dysgalactiae and Streptococcus uberis
}

\author{
Åsa Lundberg ${ }^{1,2^{*}}$, Ann Nyman $^{1}$, Helle Ericsson Unnerstad ${ }^{1}$ and Karin Persson Waller ${ }^{1,2}$
}

\begin{abstract}
Background: Streptococcus dysgalactiae and Streptococcus uberis are common causes of clinical mastitis (CM) in dairy cows. In the present study genotype variation of $S$. dysgalactiae and $S$. uberis was investigated, as well as the influence of bacterial species, or genotype within species, on the outcome of veterinary-treated CM (VTCM). Isolates of $S$. dysgalactiae $(n=132)$ and S. uberis $(n=97)$ were genotyped using pulsed-field gel electrophoresis. Identical banding patterns were called pulsotypes. Outcome measurements used were cow composite SCC, milk yield, additional registered VTCMs and culling rate during a four-month follow-up period.
\end{abstract}

Results: In total, $71 \mathrm{~S}$. dysgalactiae pulsotypes were identified. Nineteen of the pulsotypes were isolated from more than one herd; the remaining pulsotypes were only found once each in the material. All S. uberis isolates were of different pulsotypes. During the follow-up period, the SCC of $S$. dysgalactiae-cows was significantly lower than the SCC of S. uberis-cows $(P<0.05)$. Median SCC of S. dysgalactiae-cows was $71500 \mathrm{cells} / \mathrm{ml}$ and of S. uberis-cows $108000 \mathrm{celll} / \mathrm{ml}$. No other differences in outcome parameters could be identified between species or genotypes.

Conclusions: Identical S. dysgalactiae genotypes were isolated from more than one herd, suggesting some spread of this pathogen between Swedish dairy herds. The genetic variation among S. uberis isolates was substantial, and we found no evidence of spread of this pathogen between herds. The milk SCC was lower during the follow-up period if $S$. dysgalactiae rather than $S$. uberis was isolated from the case, indicating differences in treatment response between bacterial species.

Keywords: Streptococcus dysgalactiae subsp. dysgalactiae, Streptococcus uberis, Dairy cow, Veterinary-treated clinical mastitis, Genotypes, Somatic cell count, Long-term mastitis outcome, Pulsed-field gel electrophoresis, PFGE

\section{Background}

Clinical mastitis $(\mathrm{CM})$ is a common disease among dairy cows. A number of pathogens can cause $\mathrm{CM}$, but the relative importance of different pathogens differs between regions and countries in the world. In Sweden, Streptococcus dysgalactiae subsp. dysgalactiae and Streptococcus uberis are the third and fourth most common bacteria found in $\mathrm{CM}$ accounting for $15.6 \%$ and $11.1 \%$, respectively, of the cases [1].

Since the introduction of molecular bacteriology in the field of mastitis, new possibilities for studying the

\footnotetext{
* Correspondence: asa.lundberg@sva.se

'Department of Animal Health and Antimicrobial Strategies, National Veterinary Institute, SE-751 89 Uppsala, Sweden

2Department of Clinical Sciences, Swedish University of Agricultural Sciences, SE-750 07 Uppsala, Sweden
}

epidemiology of udder pathogens have emerged. S. uberis has been extensively studied at the molecular level, and pulsed-field gel electrophoresis (PFGE) has been used for genotypic characterization of $S$. uberis isolates from Europe [2], Australia [3-6], New Zealand [7], and South America [8]. A number of studies have confirmed that this pathogen predominantly shows a heterogeneous genotype pattern consistent with environmentally spread bacteria [2,3,5-7], although there is evidence that $S$. uberis also can be spread between cows as a contagious pathogen within a herd [4,9-11]. There are a few studies reporting that the same genotype can be identified in more than one herd $[4,10]$ indicating possible contagious spread with cows or equipment between herds. Molecular typing has also 
revealed differences between $S$. uberis strains in clinical manifestation [4,12] and duration of infection [13].

Although often considered as an environmental pathogen $[14,15]$, studies have also indicated that $S$. dysgalactiae may be considered a contagious pathogen [16,17]. Compared with $S$. uberis, only a few studies on genotyping of $S$. dysgalactiae isolates have been performed to our knowledge $[5,6,18]$. Within a herd, more than one strain is usually present, but a few strains are often found in multiple cows suggesting spread between cows $[5,6]$. In addition, genetically related isolates have been found on multiple farms, suggesting either contagious spread between herds [6] or a common environmental source [5].

Prudent use of antimicrobials to treat $\mathrm{CM}$ is an important part of mastitis control programs. Common aims of treatment are clinical and bacteriological cure, and a return to normal milk somatic cell count (SCC). Bacteriological cure rate have in field studies been reported to be $65-90 \%$ for $S$. dysgalactiae and 45-90\% for $S$. uberis when using treatment with benzyl penicillin or related compounds [19-21]. Detailed information on clinical cure rate is scarce, but has been reported to be $73 \%$ for S. dysgalactiae and $77 \%$ for S. uberis in one of the studies [19]. In a study on treatment of heifers for CM caused by S. dysgalactiae around calving, $15.4 \%$ of the quarters were nonfunctional and another $36.3 \%$ had an increased SCC in the milk and/or an intramammary infection 30 days after treatment [22]. The studies cited above used a follow-up period of two to four weeks after the end of treatment. To our knowledge, studies on differences in treatment outcome between $S$. dysgalactiae and $S$. uberis over a longer time period, or between genotypes within those species, have not been performed.

The understanding of infection epidemiology is essential to prevent and control mastitis. The distribution of S. dysgalactiae and $S$. uberis and genotypes within species may vary between regions and countries [23,24], but genotyping studies of those udder pathogens have, to our knowledge, not been performed in the Nordic countries, and not on a national level. The main aim of this study was, therefore, to explore the genotype variation of $S$. dysgalactiae and S. uberis associated with bovine CM in Sweden using streptococcal isolates collected in a national survey on CM. The study also aimed to investigate if bacterial species, or genotype within species, influences the outcome of veterinarytreated CM (VTCM), as measured by cow composite SCC, milk production, additional registered VTCMs and culling rate during a four month follow-up period. Differences in cow factors, geography and seasonality between CM cases due to $S$. dysgalactiae and S. uberis were also studied.

\section{Methods}

\section{Bacterial isolates}

Isolates of $S$. dysgalactiae $(\mathrm{n}=164)$ and $S$. uberis $(\mathrm{n}=117)$ were collected in a national survey on the prevalence of udder pathogens in bovine CM [1]. Case selection and diagnostic procedures have been described elsewhere [1]. In short, milk samples from cases of CM were collected by field veterinarians in 51 veterinary practices distributed all over Sweden during a one-year period. The samples were cultured at $37^{\circ} \mathrm{C}$ for $16-24$ hours on blood agar plates and evaluated in accordance with the routines of the veterinary practices. Cultured plates were sent to the National Veterinary Institute, Uppsala, Sweden where the growth was verified by routine laboratory tests. The time from day of sampling until arrival at the laboratory was 3.0 days (range 1-7 days), on average. Streptococci were identified by colony morphology, CAMP-reaction, and 12 biochemical reactions (hippurate, aesculine, salicine, sorbitol, mannitol, raffinose, lactose, saccharose, inuline, trehalose, starch and glycerine). For suspected $S$. dysgalactiae isolates not identified by the 12 biochemical reactions, Lancefield grouping (Streptex, Murex Biotech Limited, Dartford, UK) was used. To differentiate enterococci from S. uberis, growth of red colonies on SlaBa plates (Slanetz \& Bartley Medium, Oxoid Ltd., Basingstoke, England) was evaluated. Isolates were stored frozen in trypticase soy broth containing $15 \%$ glycerol.

\section{Preparation and digestion of bacterial DNA}

Isolates were thawed and cultured overnight at $37^{\circ} \mathrm{C}$ on $5 \%$ bovine blood agar supplemented with $0.05 \%$ esculine. One micro liter of $S$. dysgalactiae colony material was suspended in $250 \mu$ lysis buffer $(1 \mathrm{M} \mathrm{NaCl}, 10 \mathrm{mM}$ Tris [pH 8.0], $200 \mathrm{mM}$ EDTA, 0.5\% Sarcosyl, 0.2\% natrium deoxycholate; National Veterinary Institute, Uppsala, Sweden), mixed with $250 \mu$ l molten Agarose Prep (Amersham Biosciences, Uppsala, Sweden) and poured into plug molds (BioRad, CA, USA). Once solidified the plugs were placed in a buffer containing $5 \mathrm{ml}$ lysis buffer and $200 \mu \mathrm{l}$ lysozyme (from a stock solution of $20 \mathrm{mg} / \mathrm{ml}$; Roche Diagnostics Scandinavia AB, Bromma, Sweden) and gently shaken overnight at $37^{\circ} \mathrm{C}$. The buffer was then replaced by a proteolysis buffer containing $2.5 \mathrm{ml}$ lysis buffer and $100 \mu$ l Proteinas K (from a stock solution of $50 \mathrm{U} / \mathrm{ml}$; Roche Diagnostics Scandinavia AB, Bromma, Sweden) and the plugs were incubated for approximately $24 \mathrm{~h}$ at $56^{\circ} \mathrm{C}$ with gentle shaking. Plugs were washed twice with $10 \mathrm{ml}$ Super-Q-water (National Veterinary Institute, Uppsala, Sweden) for $20 \mathrm{~min}$ in $56^{\circ} \mathrm{C}$, and four times with $10 \mathrm{ml}$ TrisEDTA (TE) buffer (10 mM Tris [pH 8.0], $1 \mathrm{mM}$ EDTA; National Veterinary Institute, Uppsala, Sweden) for at least $20 \mathrm{~min}$ in $56^{\circ} \mathrm{C}$. For long term storage, plugs were kept at $4^{\circ} \mathrm{C}$ in $1 \mathrm{ml} \mathrm{TE}$ buffer. Before digestion, plugs were sliced in halves, and one half was equilibrated in 
$200 \mu \mathrm{l}$ CutSmart buffer (NewEngland Biolabs, MA, USA) for $30 \mathrm{~min}$ on gentle shaking at $25^{\circ} \mathrm{C}$. The rest of the plug was returned to long term storage in TE buffer. After equilibration, each plug was digested at $25^{\circ} \mathrm{C}$ overnight in a digestion solution of $100 \mu \mathrm{l}$ CutSmart buffer and $10 \mathrm{U}$ of the restriction enzyme SmaI (NewEngland Biolabs, MA, USA).

Preparation and digestion of $S$. uberis DNA was performed using the same protocol as for $S$. dysgalactiae DNA, with the exception that digestion was performed in a digestion solution containing $5 \mathrm{U}$ of SmaI.

\section{Pulsed-field gel electrophoresis}

DNA fragments were separated using a clamped homogenous electric field device (CHEF-DR II, BioRad) with pulse times of 5-15 sec over $10 \mathrm{~h}$, and 15-60 sec over $13 \mathrm{~h}$ at $6 \mathrm{~V}$, and run through a 1.2\% gel of Agarose NA (GE Healthcare, Uppsala, Sweden) in $0.5 \times$ Tris-borat EDTA-buffer (0.9 M Tris-borat, 20 mM EDTA; National Veterinary Institute, Uppsala, Sweden). Then, gels were stained with GelRed (Biotium, CA, USA).

For each bacterial species, one isolate with an easily interpreted pattern was selected among our collected isolates, as an internal reference and was run every $5^{\text {th }}$ to $6^{\text {th }}$ lane on all gels. In addition, a Lambda Ladder PFG Marker (New England Biolabs, MA, USA) was used in the first and last lane on each gel.

The protocol was repeated for untypeable isolates.

\section{Dendrogram analysis}

Macrorestriction patterns of S. dysgalactiae and S. uberis were analyzed separately. The dendrogram analyses were performed using BioNumerics software (BioNumerics Version 7.1; Applied Maths, Inc 2014; Austin, TX, USA). Similarity was computed using the Dice coefficient and an unweighted pair group method with arithmetic mean (UPGMA), with optimization set to $1.5 \%$ and the tolerance value set to $1.25 \%$. Isolates were considered to be of the same cluster if the similarity level was above $80 \%$, and of the same pulsotype when banding patterns were identical. $S$. dysgalactiae clusters were identified by capital letters, and pulsotypes within cluster with a number suffix (e.g. E1, E2, F1, F2). S. uberis clusters were identified by Roman numerals. Only clusters and pulsotypes represented by more than one isolate per genotype received an identity. The remaining genotypes were referred to as "singles".

\section{Data editing and statistical analyses Prevalence of genotypes}

In order to study the presence and distribution of different genotypes on a national level and to ensure epidemiological independence among isolates, the first isolate per species from a monoinfected cow (i.e. cows where only one bacterial species was found, and where only one udder quarter was infected) collected from each herd was included. However, if a farm had no samples collected from a monoinfected cow, the first isolate per species collected from that herd was included. Given those criteria, 135 isolates of S. dysgalactiae and 103 isolates of S. uberis were included in this part of the study. Descriptive statistics were used to present prevalence of genotypes.

\section{Differences in cow factors, season and geography}

Differences in breed of cow, parity, days in milk (DIM), season and geographic region of Sweden between $S$. dysgalactiae and $S$. uberis cases were presented using descriptive statistics.

Breed of cow was divided into three categories: Swedish Holstein (SH), Swedish Red and White (SR) and mixed breed/other breed (where the most common observation was a mix between $\mathrm{SH}$ and SR).

Parity was categorized into first, second, third, and fourth and higher lactations. Stage of lactation was categorized into first month after calving or later. Seasons were categorized into pasture season (May to August), early housing season (September to December) and late housing season (January to April). The highest subdivision of geographic regions of Sweden (eastern Sweden, southern Sweden including the islands, and northern Sweden) according to the Nomenclature of Territorial Units for Statistics (NUTS1) was used when studying geographic occurrence of strains and genotypes [25]. Associations between bacterial species and categorical variables were investigated using Fisher's exact test, as were associations between bacterial genotypes and categorical variables.

\section{Outcome measurements and cow records}

To investigate the impact of bacterial species or genotype on outcome of VTCM, only isolates from monoinfected cows were included (S. dysgalactiae: $\mathrm{n}=98 ;$ S. uberis: $\mathrm{n}=73$ ). Cow composite SCC and milk yield at test milking, recurring or new cases of VTCM (VTCMadd), and culling due to mastitis during the follow-up period were used as outcome measurements. The follow-up period was zero to 120 days after VTCM for the parameters SCC, milk yield, and culling due to mastitis, and fourteen to 120 days for VTCMadd. Day zero was defined as the day the cultured plate arrived at the National Veterinary Institute. Somatic cell count and milk yield were measured at monthly milk recordings, and this data was obtained from the Swedish Official Milk Recording Scheme (SOMRS; Swedish Dairy Association, Stockholm, Sweden).

From SOMRS, cow records including breed, parity, date of calvings, and date and cause for culling were also obtained. The criterion for culling due to mastitis was fulfilled if either the primary or secondary officially 
recorded reason for culling was mastitis or increased SCC. Disease recordings were collected from the Swedish Animal Disease Recording System (SADRS) through SOMRS. A record in the SADRS of the original VTCM was present for $92 \%$ of the cows. VTCMadd was defined as an additional record of VTCM in the SADRS during the follow-up period.

Breed, parity and calving date was also recorded in a questionnaire by the veterinarian at milk sample submission. All cows where SOMRS records and questionnaire records were consistent were eligible for inclusion in the study. In case of minor discrepancies between official cow records and questionnaire records, individual assessment of the cow's records was made before a decision was made to include or exclude the cow. In general, the official records were considered more likely to be correct. In cases of major discrepancies, the cow was included using questionnaire records only in the prevalence and risk factor part of the study, and was excluded completely from the outcome part of the study.

Eight cows were dried off or calved during the follow-up period. For these cows, only data from monthly milk recordings before dry-off was included.

Differences in outcome were calculated between the two different streptococci, between different pulsotypes and clusters within species and between groups of pulsotypes and clusters within species based on prevalence. Definitions of groups used has previously been described in Lundberg et al. [26].

Differences in SCC and milk yield between bacterial species, between genotypes or between groups of genotypes were first tested in univariable mixed-effect linear regression models with repeated measurements of monthly SCC or milk yield within cow during the follow-up period as outcome variable. Mixed-effect models were used to take into account that repeated measurements of SCC or milk yield for a certain cow might be more similar than measurements of SCC or milk yield for different cows, hence, the random effect in the mixed models was repeated measurement of SCC or milk yield and an independent covariance structure (equal variances for random effects, all covariances are zero) was used. To obtain normally distributed residuals, SCC was transformed using the Box-Cox power transformation (SCC -0.1263839-1)/-0.1263839. Bacterial species or genotype (pulsotypes, clusters, or groups of pulsotypes or clusters) were used as explanatory variables to the outcome. The cow parameters breed, parity and DIM at monthly milk recordings were included in the models as independent variables because of their possible impact on SCC and milk yield. When differences in milk yield were tested, SCC was included among independent variables and vice versa. To reduce the full models, a manual stepwise backward model selection procedure was used and only variables with a $p$-value of $\leq 0.05$ were included in the final models. Two-way interactions between the significant main effects were tested. Possible confounders were considered in all models. A variable was considered as a confounder if the point estimates of the coefficients in a model changed $>20 \%$ with the potential confounder present. The model fit of the multivariable analyses was tested by visual examination of diagnostic plots according to Dohoo et al. [27].

In addition, the proportions of cows with a SCC below 200000 cells $/ \mathrm{ml}$ at all monthly milk recordings during the follow-up period was calculated for S. dysgalactiae and $S$. uberis as well as for different genotypes or genotype groups within species. The follow-up period was shortened to 14 to 120 days to allow for SCC to normalize after therapy, and differences in proportions were tested with the Fisher's exact test. Only cows with data recorded for at least two monthly milk recordings were included in these calculations.

Proportions of cows with a VTCMadd registered and proportion of cows that were culled due to mastitis during the follow-up period were presented using descriptive statistics.

All statistical analyses were performed using Stata 13 (StataCorp, 2014; Stata Statistical Software: Release 13.1; College Station, TX, USA: StataCorp LP).

\section{Results}

\section{Macrorestriction patterns and prevalence of genotypes}

One hundred thirty two of the $S$. dysgalactiae isolates and 97 of the S. uberis isolates could be genotyped using our protocol.

Pulsed-field gel electrophoresis of $S$. dysgalactiae yielded 7 to 14 fragments in the considered size range of 45 to $500 \mathrm{~kb}$. (Additional file 1) shows a dendrogram of the results. Analysis of the $S$. dysgalactiae isolates revealed 71 pulsotypes. Nineteen of the pulsotypes could be found in two to 13 herds each (Figure 1). The remaining 52 pulsotypes were only found once each in the material. Sixty-eight of the pulsotypes could be compiled into nine clusters. Three pulsotypes could not be clustered with other pulsotypes. Six of the clusters were considered rare, each represented by two to six isolates, while three of the clusters (E, F, and G) were considered common, each represented by 30 to 40 isolates. Those three clusters accounted for $82 \%$ of the isolates (Table 1).

Pulsed field gel electrophoresis of S. uberis yielded 10 to 13 fragments in the $40-660 \mathrm{~kb}$ size range. (Additional file 2) shows a dendrogram of the results. All 97 S. uberis isolates were found to be of different pulsotypes. Fortyfive isolates belonged to 21 clusters; the remaining isolates could not be assigned to a cluster (Additional file 2). Each cluster was represented by two or three isolates. 


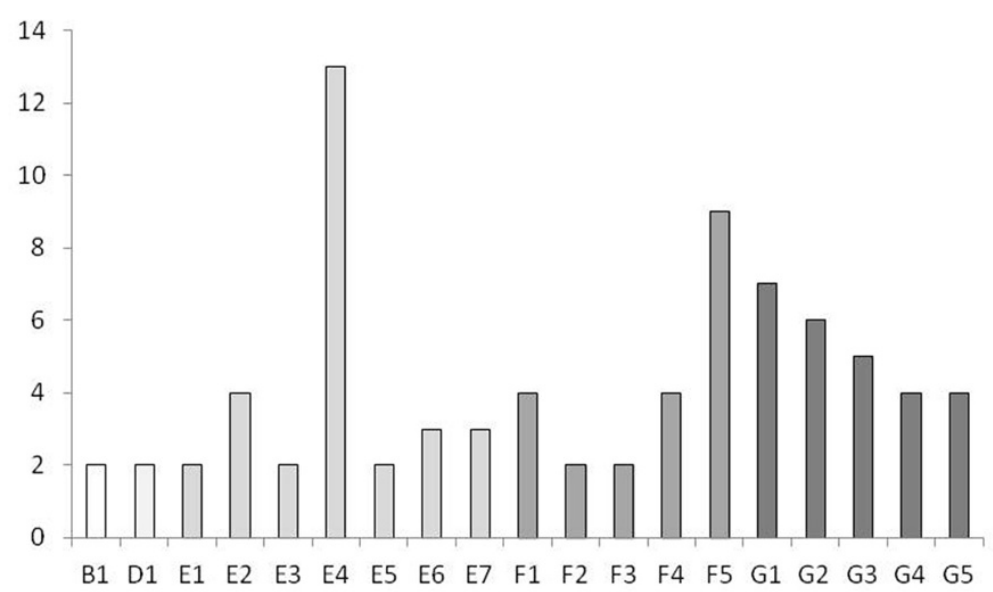

Figure 1 Numbers of Streptococcus dysgalactiae isolates of different pulsotypes. Numbers of epidemiologically independent Streptococcus dysgalactiae isolates of different pulsotypes from cases of veterinary-treated clinical mastitis in Sweden (pulsotypes only isolated once $(n=52)$ are not included). Pulsotypes belonging to the same cluster share the same color.

\section{Differences in cow factors, season and geography} between S. dysgalactiae and S. uberis

Descriptive statistics are given in Table 2. A larger proportion of $S$. uberis-isolates than of $S$. dysgalactiae-isolates came from cows of the $\mathrm{SH}$ breed compared to cows of the SR breed, but the difference was not statistically significant $(P=0.079)$. The distribution of parities and stage of lactation was similar among $S$. dysgalactiae and $S$. uberis isolates. About half of the isolates came from cases of VTCM occurring during the first month of lactation, with the rest spread out throughout the lactation.

There was a significant difference in occurrence of $S$. dysgalactiae and $S$. uberis over seasons $(P<0.05$; Table 2$)$. The occurrence of $S$. uberis was lowest during the late

Table 1 Numbers (n) and percentages (\%) of epidemiologically independent Streptococcus dysgalactiae isolates from cases of veterinary-treated clinical mastitis in Sweden divided into clusters after genotyping by pulsed-field gel electrophoresis and clustering at the level of $\mathbf{8 0} \%$ genetic similarity

\begin{tabular}{ll}
\hline Cluster & $\mathbf{n}(\%)$ \\
\hline A & $3(2.3)$ \\
B & $6(4.6)$ \\
C & $2(1.5)$ \\
D & $5(3.8)$ \\
E & $40(30.3)$ \\
F & $30(22.7)$ \\
G & $38(28.8)$ \\
H & $3(2.3)$ \\
I & $2(1.5)$ \\
Singles & $3(2.3)$ \\
Total & $132(100)$ \\
\hline
\end{tabular}

housing season; no fluctuations throughout the year could be seen for S. dysgalactiae.

The majority of both $S$. dysgalactiae and $S$. uberis isolates came from Southern Sweden. A larger proportion of $S$. uberis-isolates than of $S$. dysgalactiae-isolates came from Northern Sweden, and the opposite was found for Southern Sweden, but the difference was not significant $(P=0.08)$. The geographic distribution of the isolates within the country is given in Figure 2.

\section{Differences in cow factors, season and geography} between bacterial genotypes within species

For $S$. dysgalactiae, the number of isolates per pulsotype and most clusters were small, and statistical analyses of differences between groups were therefore not performed. Some pulsotypes could, however, only be found in one breed, lactation stage or parity, or during one season or in a specific region. The distribution of clusters, or groups of pulsotypes or clusters, did not indicate any trends related to cow factors, season or geography.

Due to few cows in each $S$. uberis cluster, statistical analyses of differences between clusters were not performed and no trends could be identified.

\section{Differences in outcome between S. dysgalactiae and \\ S. uberis}

For 163 monoinfected cows (95 S. dysgalactiae-cows and $68 \mathrm{~S}$. uberis-cows) results from at least one monthly milk recording after the VTCM were available. In total, 541 monthly SCC and milk yield recordings were included (3.3 recordings per cow, on average).

During the follow-up period after the VTCM, the SCC of $S$. dysgalactiae-cows was significantly lower than the SCC of S. uberis-cows ( $<<0.05$; Figure 3 ). The median SCC during the follow-up period was 71500 cells/ml 


\begin{tabular}{|c|c|c|c|}
\hline Variable & Class & $\begin{array}{l}\text { S. dysgalactiae, } \\
\text { n (\%) }\end{array}$ & $\begin{array}{l}\text { S. uberis, } \\
\text { n (\%) }\end{array}$ \\
\hline \multirow[t]{3}{*}{ Breed $^{1}$} & $S R$ & $67(49.6)$ & $38(36.9)$ \\
\hline & $\mathrm{SH}$ & $62(45.9)$ & $58(56.3)$ \\
\hline & Other & $6(4.4)$ & $7(6.8)$ \\
\hline \multirow[t]{4}{*}{ Parity } & First & $56(41.5)$ & $42(40.8)$ \\
\hline & Second & $30(22.2)$ & $22(21.4)$ \\
\hline & Third & $21(15.6)$ & $18(17.5)$ \\
\hline & Fourth or higher & $28(20.7)$ & $21(20.4)$ \\
\hline \multirow[t]{2}{*}{ Stage of lactation } & $<30$ days postpartum & $68(50.4)$ & $44(42.3)$ \\
\hline & $\geq 30$ days postpartum & 67 (49.6) & $59(57.3)$ \\
\hline \multirow[t]{3}{*}{ Season } & Early housing ${ }^{2}$ & 48 (35.6) & $43(41.8)$ \\
\hline & Late housing ${ }^{3}$ & $47(34.8)$ & $23(22.3)$ \\
\hline & Pasture $^{4}$ & 40 (29.6) & 37 (35.9) \\
\hline \multirow[t]{3}{*}{ Region } & Southern Sweden & $91(67.4)$ & $59(57.3)$ \\
\hline & Eastern Sweden & $26(19.3)$ & $21(20.4)$ \\
\hline & Northern Sweden & $18(13.3)$ & $23(22.3)$ \\
\hline
\end{tabular}

${ }^{1} \mathrm{SR}=$ Swedish Red, SH = Swedish Holstein; ${ }^{2}$ September-December; ${ }^{3}$ January-April; ${ }^{4}$ May-August.

( $1^{\text {st }}$ quartile: 35 500; $3^{\text {rd }}$ quartile: 203500$)$ and 108000 cells $/ \mathrm{ml}\left(1^{\text {st }}\right.$ quartile: $47000 ; 3^{\text {rd }}$ quartile: 319000 for $S$. dysgalactiae-cows and S. uberis-cows, respectively. The difference in SCC between species remained in the multivariable model when the influence of milk yield, parity, breed and DIM on SCC also was considered (Table 3).

Eighty-four S. dysgalactiae-cows and 58 S. uberis-cows had more than one registered recording of SCC during the period of 14 to 120 days after VTCM. The proportion of S. dysgalactiae-cows with a SCC below 200000 cells $/ \mathrm{ml}$ at all recordings during this period was 58\%. The corresponding percentage for $S$. uberis-cows was $43 \%$. The difference between species was not significant $(P=0.09)$.

The average daily milk yield at monthly milk recordings during the follow-up period was $28.5 \mathrm{~kg}$ (range: $9.2-50.8 \mathrm{~kg}$ ) and $29.3 \mathrm{~kg}$ (range: $9.8-53.6 \mathrm{~kg}$ ) for $S$. dysgalactiae-cows and $S$. uberis-cows, respectively, and did not differ significantly between species.

Eleven (12\%) S. dysgalactiae-cows had a VTCMadd registered and six (6\%) were culled during the followup period. The corresponding numbers for S. uberiscows were six (9\%) with VTCMadd and six (8\%) culled.

\section{Differences in outcome between bacterial genotypes within species}

No univariable associations between milk yield or SCC and bacterial species or genotype or groups of genotypes could be found. However, there seemed to be some indication that the proportion of $S$. dysgalactiae cows having SCC constantly below 200000 cells/ml during the follow-up period varied between pulsotypes (Table 4), although the numbers of isolates in each group were too small for statistical analyses.

The number of cows within each pulsotype or cluster of S. dysgalactiae and S. uberis, or within each group of pulsotypes or clusters, that had a VTCMadd registered or that were culled during the follow-up period was too small for statistical analysis and no trends could be identified.

\section{Discussion}

\section{Genotype distribution}

In line with most previous studies [2,3,5-7], we found that the genotype pattern of S. uberis is heterogeneous in Sweden and we found no evidence of contagious spread of $S$. uberis between herds as all isolates investigated were of different pulsotypes. In contrast, identical pulsotypes of $S$. dysgalactiae were found in multiple herds in the present study, although 39\% of the isolates belonged to unique pulsotypes. The findings of identical strains of $S$. dysgalactiae in different herds is in line with previous studies [5,6,11]. A common environmental source could explain why the same genotype was found in multiple herds, but this hypothesis seems less likely for many of the genotypes since identical isolates were found in separate parts of the country. Trade of infected animals is another, and perhaps more likely, way of spread of the pathogen between herds and it has been shown that the trade of livestock is expansive within Sweden [28]. For local spread (kilometers) the fly Hydrotaea irritans, which can act as a vector for $S$. dysgalactiae [29], could also be involved. It is possible that some genotypes contain virulence factors that make them especially apt to spreading between cows. No such attributes of the strains were investigated in this study, but previous studies have shown strain differences in virulence factors, possibly connected to spread between cows, for both S. dysgalactiae and S. uberis [30].

Given the existing information and the original study design, it was not possible to study the genetic withinherd variation among the udder pathogens. Previous studies of both S. dysgalactiae and S. uberis have, however, shown that several strains can be found in a herd and that in some instances one or a few of these strains can be found in other herds as well $[4,6,10]$. It is therefore possible that we, when including only one sample per herd, might have underestimated the spread of 


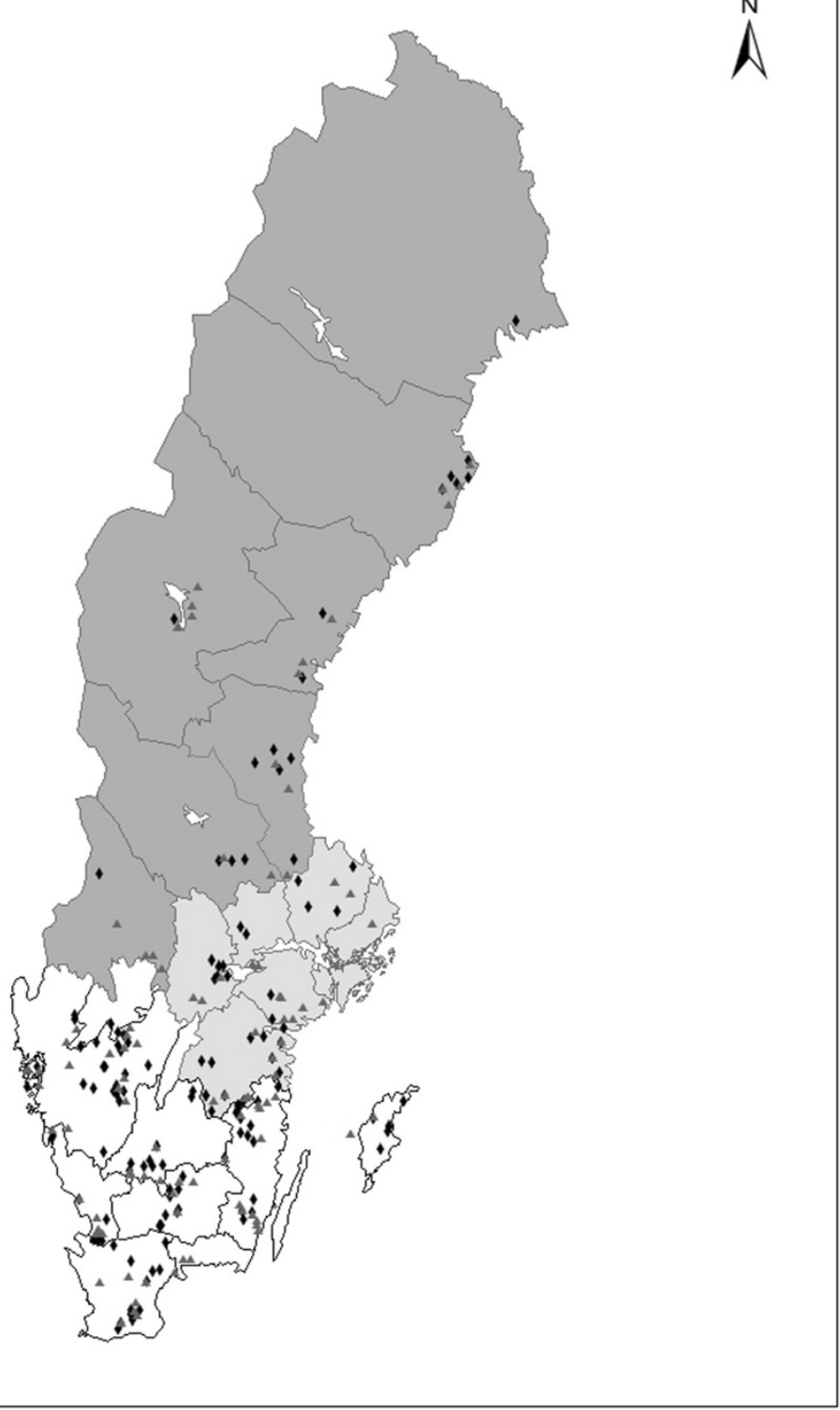

Figure 2 Geographic distribution of cases of clinical mastitis. Geographic distribution of cases of veterinary-treated clinical mastitis caused by Streptococcus dysgalactiae (black diamonds) and Streptococcus uberis (grey triangles).

genotypes between herds for both $S$. dysgalactiae and $S$. uberis in the present study.

The moderate and large genotypic variation found for $S$. dysgalactiae and S. uberis, respectively, in the present study differs markedly from a previous study on isolates of Staphylococcus aureus from the same national survey [26]. In that study, almost two thirds of the $S$. aureus isolates belonged to two pulsotypes, emphasizing the contagious nature of $S$. aureus as opposed to the two streptococcal species investigated in the present study.

\section{Differences in outcome of VTCM between bacterial species and genotypes}

Cows veterinary-treated for CM caused by $S$. dysgalactiae had a lower SCC during the follow-up period, than did cows treated for infections caused by S. uberis. Possible explanations for this finding could be a stronger inflammatory response to $S$. uberis at the initial infection [31] or difference in bacteriological cure rates between species [19].

In the present study, we did not have any information on SCC at the time of VTCM other than the California 


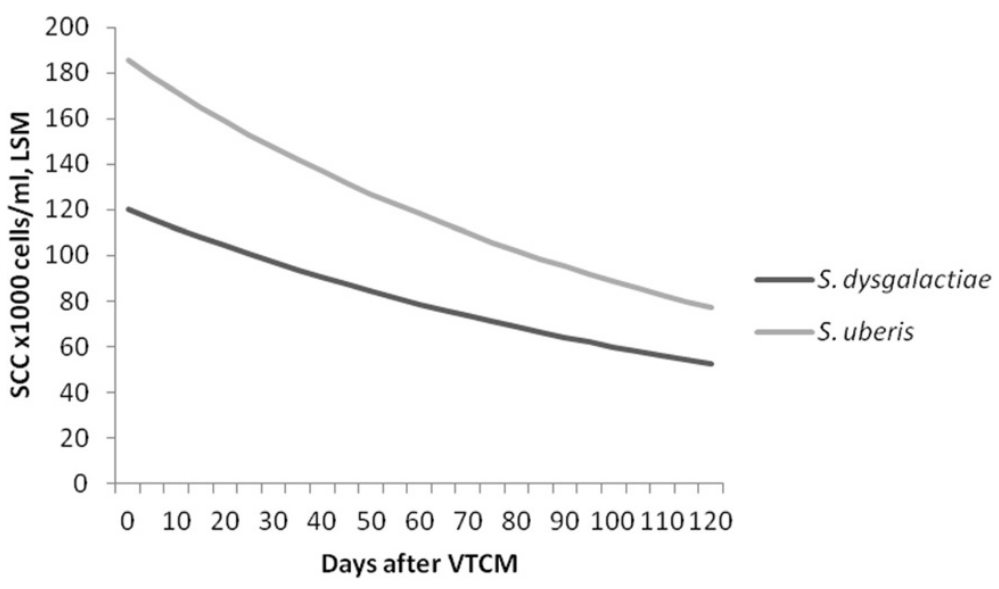

Figure 3 Long-term outcome after clinical mastitis as measured by SCC. Least square means (LSM) of cow somatic cell counts (SCC; $\times 1000$ cells $/ \mathrm{ml}$ ) at monthly milk recordings after veterinary-treated cases of clinical mastitis (VTCM) from the results of a multivariable mixed-effect linear regression model investigating associations between Streptococcus dysgalactiae and Streptococcus uberis.

Table 3 Final hierarchical multivariable linear-regression analysis of variables significantly $(P<0.05)$ associated with somatic cell count (SCC; transformed using the BoxCox power transformation) at monthly milk recordings during a follow-up period of 120 days after a veterinary treated clinical mastitis

\begin{tabular}{llllll}
\hline Variable $^{1}$ & $\boldsymbol{\beta}$ & S.E. $(\boldsymbol{\beta})$ & $\boldsymbol{P}$-value & LSM $^{2}$ & $\mathbf{9 5 \%}$ Cl (LSM) \\
\hline Intercept & 3.996 & 0.17 & - & - & -
\end{tabular}

Bacterial finding

$\begin{array}{llllll}\text { S. dysgalactiae } & \text { Ref. }^{3} & - & - & 86.6 & 70.1,107.5 \\ \text { S. uberis } & 0.260 & 0.093 & 0.005 & 138.6 & 106.3,182.6\end{array}$

Other factors

Parity

\begin{tabular}{llllll} 
First & Ref. & - & - & 75.9 & $59.8,97.1$ \\
Second & 0.219 & 0.113 & 0.051 & 112.0 & $82.8,153.4$ \\
Third & 0.169 & 0.137 & 0.218 & 102.3 & $68.7,155.6$ \\
Fourth or higher & 0.433 & 0.136 & 0.001 & 260.5 & $109.1,260.5$ \\
Milk yield & -0.002 & 0.0005 & 0.000 & - & - \\
At Q1: $23.8 \mathrm{~kg}$ & - & - & - & 132.8 & $108.1,164.2$ \\
At Q2: $28.7 \mathrm{~kg}$ & - & - & - & 109.8 & $92.0,131.4$ \\
At Q3: $33.4 \mathrm{~kg}$ & - & - & - & 91.8 & $76.3,111.0$ \\
Days in milk & -0.001 & 0.0004 & 0.001 & - & - \\
At Q1: 67 days & - & - & - & 129.4 & $105.0,160.5$ \\
At Q2: 115 days & - & - & - & 115.6 & $96.4,139.3$ \\
At Q3: 188 days & - & - & - & 97.8 & $81.5,117.7$ \\
\hline
\end{tabular}

${ }^{1} \mathrm{Q} 1, \mathrm{Q}$, and Q3 = first quartile, second quartile/median, and third quartile, respectively.

${ }^{2}$ Least square means (LSM) of Box-Cox transformed SCC back-transformed to original scale $(\times 1000 / \mathrm{ml})$ presented by variable.

${ }^{3}$ Ref. $=$ Reference category.
Table 4 Numbers of cows with a somatic cell count (SCC) below 200000 cells $/ \mathrm{ml}$ at all monthly milk recordings, and number of cows with SCC above 200000 cells $/ \mathrm{ml}$ at least one monthly milk recording 14 to 120 days after veterinary-treated clinical mastitis, caused by different clusters or pulsotypes 1 of Streptococcus dysgalactiae

\begin{tabular}{|c|c|c|c|}
\hline Cluster/Pulsotype & $<200000$ cells $/ \mathrm{ml}$ & $>200000$ cells $/ \mathrm{ml}$ & Total \\
\hline A & 2 & 1 & 3 \\
\hline B & 2 & 3 & 5 \\
\hline B1 & 0 & 2 & 2 \\
\hline $\mathrm{D}$ & 1 & 1 & 2 \\
\hline$E$ & 14 & 10 & 24 \\
\hline E2 & 1 & 2 & 3 \\
\hline E4 & 5 & 2 & 7 \\
\hline E5 & 1 & 1 & 2 \\
\hline E6 & 1 & 2 & 3 \\
\hline E7 & 2 & 1 & 3 \\
\hline $\mathrm{F}$ & 11 & 6 & 17 \\
\hline F1 & 1 & 2 & 3 \\
\hline F4 & 4 & 0 & 4 \\
\hline F5 & 5 & 1 & 6 \\
\hline G & 13 & 12 & 25 \\
\hline G1 & 1 & 5 & 6 \\
\hline $\mathrm{G} 2$ & 3 & 1 & 4 \\
\hline G3 & 2 & 1 & 3 \\
\hline G4 & 1 & 2 & 3 \\
\hline G5 & 2 & 1 & 3 \\
\hline $\mathrm{H}$ & 1 & 1 & 2 \\
\hline
\end{tabular}

${ }^{1}$ Cows infected with unique clusters/pulsotypes are not included in the table. 
Mastitis Test (CMT) score performed by the investigating veterinarian. The CMT is, however, an imprecise test, and most cases of CM are categorized as either 4 or 5 on the Nordic scale (i.e. SCC $>\sim 800000$ cells $/ \mathrm{ml}$ ) making CMT unsuitable for use in the present study.

Unfortunately, no information about bacteriological cure after VTCM was available in our study material. National guidelines at the time of sampling stated that infections during lactation caused by $S$. dysgalactiae and $S$. uberis should be treated by parenteral benzyl penicillin for 4-5 days [32]. The isolates in the present study were tested for susceptibility to penicillin in vitro [33]. All of the $S$. dysgalactiae isolates and $94 \%$ of the $S$. uberis isolates tested were susceptible, therefore it seems unlikely that any possible difference in bacteriological cure was due to resistance to penicillin.

No statistically significant differences in SCC between genotypes, or groups of genotypes, within bacterial species could be found in this study. The number of genotypes in relation to the total number of isolates was high, which made comparisons difficult. The discriminatory power of PFGE is high, making it probable that isolates with identical PFGE patterns are in fact genetically related. Tenover et al. [34] proposed that genotypes with a one to three band difference (consistent with one genetic event) are closely related and that genotypes with a four to six band difference are possibly related. This was, however, proposed for hospital outbreaks and to our knowledge, similar guidelines for national surveillance material do not exist. It is therefore not certain that isolates with the $80 \%$ level of genetic similarity used for clustering in the present study are related. This could explain why differences in our outcome parameters could not be found between $S$. dysgalactiae clusters. To further study if differences in outcome of VTCM could be attributed to bacterial genotypes of $S$. dysgalactiae or S. uberis, a study including a larger number of natural infections could be used, resulting in more isolates per pulsotype or cluster and enabling statistical comparisons. In experimental infections, significant differences in pathogenicity between different strains of $S$. dysgalactiae [35], as well as between different strains of S. uberis [36], have been shown in the past, and another option may be to study long-term outcome after experimental infections of isolates of different genotypes. However, it is also possible that isolates of the same pulsotype or cluster express different virulence factors. Further studies in this area are therefore warranted.

We found no differences in milk yield between bacterial species, or between genotypes within species. As milk yield and SCC are correlated, i.e. the milk yield decreases with increasing SCC [37] and we found a difference in SCC between streptococcal species, a difference in milk yield between $S$. dysgalactiae and $S$. uberis during the follow-up period would have been expected. It is possible; however, that the difference in SCC between species was too small to influence the milk yield significantly. It is also possible that $S$. uberis infections are more common in high yielding cows, but since information on milk yield before VTCM was not available in the present study this could not be controlled for in the comparison between bacterial species.

\section{Species and genotype differences in cow factors, season and geography}

The results indicate that breed, season and geographical region, but not parity and stage of lactation, might differ between cases of VTCM due to $S$. dysgalactiae and $S$. uberis in Sweden. However, the results should be interpreted with caution as the study was not designed specifically for evaluation of the effect of cow factors, season and geography on the risk for infection with different streptococci. For example, information about other, possibly confounding, factors, like herd size, barn type and breed distribution in herds and over geographic regions, were not available in this study and thus could not be controlled for in the statistical analysis. The study material was, however, representative for VTCM on a national level as the selection of cases was based on the distribution of cows throughout the country.

The lower and higher proportion of S. uberis in the late housing season and in $\mathrm{SH}$ cows, respectively, compared to $S$. dysgalactiae is in line with the previous study where the occurrence of VTCM caused by S. uberis was compared to VTCM caused by all other pathogens [1]. The seasonal pattern is also similar to the results of a Canadian study, where the incidence rate of CM caused by $S$. uberis was low during the winter and peaked in August [38]. However, in Canada there seemed to be a decline in $S$. dysgalactiae incidence rate during the summer as well [38], a pattern not seen in our material. Moreover, regional differences have been described for S. dysgalactiae in Canada [24], but have to our knowledge not been described for $S$. uberis.

As already mentioned, parity did not differ between cases of S. dysgalactiae and S. uberis mastitis. Unpublished observations suggest, however, that mastitis cases due to the two streptococcal species investigated in the present study are more prevalent in first parity cows compared to clinical cases of Staphylococcus aureus mastitis studied in a previous paper [26]. The CM cases of the two studies originated from the same national survey.

The effect of DIM on the distribution of CM caused by $S$. uberis in this study seem to differ from that reported from New Zealand where S. uberis is predominantly isolated during the first month of lactation [39]. 
These differences between countries may be due to different production systems.

\section{Conclusions}

Identical S. dysgalactiae genotypes were found in cases of bovine CM from more than one herd, indicating some spread of infections between Swedish dairy herds, but a large proportion of the banding patterns were only found once. In contrast, we found no evidence of spread of $S$. uberis genotypes between herds. The genetic variation among S. uberis isolates was substantial. The results suggest that, in Sweden, S. uberis should be considered as an environmental pathogen, while $S$. dysgalactiae probably can act either as a contagious or an environmental pathogen, at least when considering spread between herds. The only outcome of veterinary-treated CM that differed significantly between bacterial species or genotypes was the milk SCC, which was lower during a four month followup period after veterinary treatment of CM if $S$. dysgalactiae rather than S. uberis was isolated from the case.

\section{Additional files}

Additional file 1: Dendrogram of S. dysgalactiae. Dendrogram of pulsed-field gel electrophoresis profiles of epidemiologically independent Streptococcus dysgalactiae isolates collected from cases of veterinary-treated clinical mastitis in Sweden. Isolate code (IDnr.), cluster name (Cl.) and pulsotype names (PT) are shown, as well as the $80 \%$ cutoff line (vertical line) for clusters.

Additional file 2: Dendrogram of S. uberis. Dendrogram of pulsed-field gel electrophoresis profiles of epidemiologically independent Streptococcus uberis isolates collected from cases of bovine clinical mastitis in Sweden. Isolate code (IDnr.) and cluster (Cl.) names are shown, as well as the 80\% cutoff line (vertical line) for clusters.

\begin{abstract}
Abbreviations
NUTS: Nomenclature of Territorial Units for Statistics; PFGE: Pulsed-field gel electrophoresis; SCC: Somatic cell count; SOMRS: Swedish Official Milk Recording Scheme; SADRS: Swedish Animal Disease Recording System; VTCM: Veterinary-treated clinical mastitis; VTCMadd: Additional episodes of VTCM for the same cow.
\end{abstract}

\section{Competing interests}

The authors declare that they have no competing interests.

\section{Authors' contributions}

All authors participated in the design of the study. ÅL participated in the genotyping, carried out the statistical analyses and drafted the manuscript. AN participated in the statistical analyses. HEU participated in the bacteriological analyses. KPW coordinated the study and helped draft the manuscript. All authors read and approved the final manuscript.

\section{Acknowledgements}

The authors would like to thank the Swedish Dairy Association/Växa Sverige for contributing data, and Maria Persson for performing most of the laboratory work. Thanks also to Anna Aspán at the National Veterinary Institute and Karin Östensson at the Swedish University of Agricultural Sciences. The project was funded by the Swedish Research Council for Environment, Agricultural Sciences and Spatial Planning (Formas), and the Swedish Farmers' Foundation for Agricultural Research.

Received: 8 July 2014 Accepted: 14 November 2014

Published online: 27 November 2014

\section{References}

1. Ericsson Unnerstad H, Lindberg A, Persson Waller K, Ekman T, Artursson K, Nilsson-Ost M, Bengtsson B: Microbial aetiology of acute clinical mastitis and agent-specific risk factors. Vet Microbiol 2009, 137:90-97.

2. Khan IU, Hassan AA, Abdulmawjood A, Lämmler C, Wolter W, Zschöck M: Identification and epidemiological characterization of Streptococcus uberis isolated from bovine mastitis using conventional and molecular methods. J Vet Sci 2003, 4:213-224.

3. Abureema S, Smooker P, Malmo J, Deighton M: Molecular epidemiology of recurrent clinical mastitis due to Streptococcus uberis: evidence of both an environmental source and recurring infection with the same strain. J Dairy Sci 2014, 97:285-290.

4. Phuektes P, Mansell PD, Dyson RS, Hooper ND, Dick JS, Browning GF: Molecular epidemiology of Streptococcus uberis isolates from dairy cows with mastitis. J Clin Microbiol 2001, 39:1460-1466.

5. Baseggio N, Mansell PD, Browning JW, Browning GF: Strain differentiation of isolates of streptococci from bovine mastitis by pulsed-field gel electrophoresis. Mol Cell Probes 1997, 11:349-354.

6. Wang SM, Deighton MA, Capstick JA, Gerraty N: Epidemiological typing of bovine streptococci by pulsed-field gel electrophoresis. Epidemiol Infect 1999, 123:317-324

7. McDougall S, Parkinson TJ, Leyland M, Anniss FM, Fenwick SG: Duration of infection and strain variation in Streptococcus uberis isolated from cows' milk. J Dairy Sci 2004, 87:2062-2072.

8. Lasagno MC, Reinoso EB, Dieser SA, Calvinho LF, Buzzola F, Vissio C, Bogni Cl, Odierno LM: Phenotypic and genotypic characterization of Streptococcus uberis isolated from bovine subclinical mastitis in Argentinean dairy farms. Rev Argent Microbiol 2011, 43:212-217.

9. Zadoks RN, Allore HG, Barkema HW, Sampimon OC, Gröhn YT, Schukken YH: Analysis of an outbreak of Streptococcus uberis mastitis. J Dairy Sci 2001, 84:590-599.

10. Coffey TJ, Pullinger GD, Urwin R, Jolley KA, Wilson SM, Maiden MC, Leigh JA: First insights into the evolution of Streptococcus uberis: a multilocus sequence typing scheme that enables investigation of its population biology. Appl Environ Microbiol 2006, 72:1420-1428.

11. Rato MG, Bexiga R, Nunes SF, Cavaco LM, Vilela CL, Santos-Sanches : Molecular epidemiology and population structure of bovine Streptococcus uberis. J Dairy Sci 2008, 91:4542-4551.

12. Pullinger GD, Coffey TJ, Maiden MC, Leigh JA: Multilocus-sequence typing analysis reveals similar populations of Streptococcus uberis are responsible for bovine intramammary infections of short and long duration. Vet Microbiol 2007, 119:194-204.

13. Zadoks RN, Gillespie BE, Barkema HW, Sampimon OC, Oliver SP, Schukken YH: Clinical, epidemiological and molecular characteristics of Streptococcus uberis infections in dairy herds. Epidemiol Infect 2003, 130:335-349.

14. Todhunter DA, Smith KL, Hogan JS: Environmental streptococcal intramammary infections of the bovine mammary gland. J Dairy Sci 1995, 78:2366-2374

15. Gillespie BE, Jayarao BM, Pankey JW, Oliver SP: Subtyping of Streptococcus dysgalactiae and Streptococcus uberis isolated from bovine mammary secretions by DNA fingerprinting. Zentralblatt Für Veterinärmedizin Reihe $B J$ Vet Med Ser B 1998, 45:585-593.

16. Barkema HW, Schukken YH, Lam TJ, Beiboer ML, Benedictus G, Brand A: Management practices associated with the incidence rate of clinical mastitis. J Dairy Sci 1999, 82:1643-1654.

17. Fox LK, Gay JM: Contagious mastitis. Vet Clin North Am Food Anim Pract 1993, 9:475-487.

18. Bert F, Branger C, Poutrel B, Lambert-Zechovsky N: Differentiation of human and animal strains of Streptococcus dysgalactiae by pulsed-field gel electrophoresis. FEMS Microbiol Lett 1997, 150:107-112.

19. Kalmus $P$, Simojoki H, Orro T, Taponen S, Mustonen K, Holopainen J, Pyörälä S: Efficacy of 5-day parenteral versus intramammary benzylpenicillin for treatment of clinical mastitis caused by gram-positive bacteria susceptible to penicillin in vitro. J Dairy Sci 2014, 97:2155-2164.

20. McDougall S, Agnew KE, Cursons R, Hou XX, Compton CRW: Parenteral treatment of clinical mastitis with tylosin base or penethamate hydriodide in dairy cattle. J Dairy Sci 2007, 90:779-789.

21. Taponen S, Dredge K, Henriksson B, Pyyhtiä A-M, Suojala L, Junni R, Heinonen $K$, Pyörälä S: Efficacy of intramammary treatment with procaine penicillin $G$ vs. procaine penicillin $\mathrm{G}$ plus neomycin in bovine clinical mastitis caused by 
penicillin-susceptible, gram-positive bacteria-a double blind field study. J Vet Pharmacol Ther 2003, 26:193-198.

22. Waage S, Skei HR, Rise J, Rogdo T, Sviland S, Odegaard SA: Outcome of clinical mastitis in dairy heifers assessed by reexamination of cases one month after treatment. J Dairy Sci 2000, 83:70-76.

23. Douglas VL, Fenwick SG, Pfeiffer DU, Williamson NB, Holmes CW: Genomic typing of Streptococcus uberis isolates from cases of mastitis, in New Zealand dairy cows, using pulsed-field gel electrophoresis. Vet Microbiol 2000, 75:27-41.

24. Olde Riekerink RGM, Barkema HW, Kelton DF, Scholl DT: Incidence rate of clinical mastitis on Canadian dairy farms. J Dairy Sci 2008, 91:1366-1377.

25. European Union: Regulation (EC) no 1059/2003 of the European parliament and of the council of 26 May 2003 on the establishment of a common classification of territorial units for statistics (NUTS). Off J EU 2003, 1059/2003:L154/151-L154/141.

26. Lundberg A, Aspán A, Nyman A, Unnerstad HE, Waller KP: Associations between bacterial genotype and outcome of bovine clinical Staphylococcus aureus mastitis. Acta Vet Scand 2014, 56:2.

27. Dohoo I, Martin W, Stryhn H: Veterinary Epidemiologic Research. 2nd edition. VER Inc: Charlottetown, Prince Edward Islands, Canada; 2010.

28. Widgren S, Frössling J: Spatio-temporal evaluation of cattle trade in Sweden: description of a grid network visualization technique. Geospatial Health 2010 5:119-130.

29. Chirico J, Jonsson P, Kjellberg S, Thomas G: Summer mastitis experimentally induced by Hydrotaea irritans exposed to bacteria. Med Vet Entomol 1997, 11:187-192.

30. Frost AJ, Wanasinghe DD, Woolcock JB: Some factors affecting selective adherence of microorganisms in the bovine mammary gland. Infect Immun 1977, 15:245-253.

31. Schepers AJ, Lam TJ, Schukken YH, Wilmink JB, Hanekamp WJ: Estimation of variance components for somatic cell counts to determine thresholds for uninfected quarters. J Dairy Sci 1997, 80:1833-1840.

32. Ekman T, Franklin A, Hallén Sandgren C, Jonsson P: Proposed treatment of clinical mastitis in cows [in Swedish]. Sven Vet Tidn 1995, 47:713-718.

33. Bengtsson B, Unnerstad HE, Ekman T, Artursson K, Nilsson-Ost M, Waller KP: Antimicrobial susceptibility of udder pathogens from cases of acute clinical mastitis in dairy cows. Vet Microbiol 2009, 136:142-149.

34. Tenover FC, Arbeit RD, Goering RV, Mickelsen PA, Murray BE, Persing DH, Swaminathan B: Interpreting chromosomal DNA restriction patterns produced by pulsed-field gel electrophoresis: criteria for bacterial strain typing. J Clin Microbiol 1995, 33:2233-2239.

35. Higgs TM, Neave FK, Bramley AJ: Differences in intramammary pathogenicity of four strains of Streptococcus dysgalactiae. J Med Microbiol 1980, 13:393-399.

36. Tassi R, MCNeilly TN, Fitzpatrick JL, Fontaine MC, Reddick D, Ramage C, Lutton M, Schukken YH, Zadoks RN: Strain-specific pathogenicity of putative host-adapted and nonadapted strains of Streptococcus uberis in dairy cattle. J Dairy Sci 2013, 96:5129-5145.

37. Hand KJ, Godkin A, Kelton DF: Milk production and somatic cell counts: a cow-level analysis. J Dairy Sci 2012, 95:1358-1362.

38. Olde Riekerink RGM, Barkema HW, Stryhn H: The effect of season on somatic cell count and the incidence of clinical mastitis. J Dairy Sci 2007 90:1704-1715.

39. McDougall S: Intramammary treatment of clinical mastitis of dairy cows with a combination of lincomycin and neomycin, or penicillin and dihydrostreptomycin. $N$ Z Vet J 2003, 51:111-116.

\section{Submit your next manuscript to BioMed Central and take full advantage of:}

- Convenient online submission

- Thorough peer review

- No space constraints or color figure charges

- Immediate publication on acceptance

- Inclusion in PubMed, CAS, Scopus and Google Scholar

- Research which is freely available for redistribution

Submit your manuscript at www.biomedcentral.com/submit 